\title{
Rhinovirus Infection and Familial Atopy Predict Persistent Asthma and Sensitisation 7 Years after a First Episode of Acute Bronchiolitis in Infancy
}

\author{
Julie Magnier ${ }^{1}$, Valérie Julian ${ }^{2} \mathbb{D}$, Aurélien Mulliez ${ }^{3} \mathbb{D}$, Alexandra Usclade ${ }^{4}$, Emmanuelle Rochette ${ }^{1,4, *} \mathbb{D}$, \\ Bertrand Evrard ${ }^{5,6}$, Flore Amat ${ }^{7}$ and Carole Egron ${ }^{1}$
}

\section{check for} updates

Citation: Magnier, J.; Julian, V.; Mulliez, A.; Usclade, A.; Rochette, E.; Evrard, B.; Amat, F.; Egron, C. Rhinovirus Infection and Familial Atopy Predict Persistent Asthma and Sensitisation 7 Years after a First Episode of Acute Bronchiolitis in Infancy. Children 2021, 8, 850. https://doi.org/10.3390/ children 8100850

Academic Editor: Cilla Söderhäll

Received: 24 August 2021

Accepted: 24 September 2021

Published: 26 September 2021

Publisher's Note: MDPI stays neutral with regard to jurisdictional claims in published maps and institutional affiliations.

Copyright: (c) 2021 by the authors Licensee MDPI, Basel, Switzerland. This article is an open access article distributed under the terms and conditions of the Creative Commons Attribution (CC BY) license (https:/ / creativecommons.org/licenses/by/ $4.0 /)$.
1 CHU Clermont-Ferrand, Pôle Pédiatrique, Unité d'allergologie de l'enfant, CHU Estaing, 1 Place Lucie et Raymond Aubrac, F-63003 Clermont-Ferrand, France; jmagnier@chu-clermontferrand.fr (J.M.); cegron@chu-clermontferrand.fr (C.E.)

2 Department of Sport Medicine and Functional Explorations, Diet and Musculoskeletal Health Team, CRNH, INRA, University Teaching Hospital of Clermont-Ferrand, University of Clermont Auvergne, F-63003 Clermont-Ferrand, France; vjulian@chu-clermontferrand.fr

3 CHU Clermont-Ferrand, Unité de Biostatistiques, Direction de la Recherche Clinique et Innovation (DRCI), 58 Rue Montalembert, F-63003 Clermont-Ferrand, France; amulliez@chu-clermontferrand.fr

4 CHU Clermont-Ferrand, INSERM CIC 1405, F-63003 Clermont-Ferrand, France; ausclade@chu-clermontferrand.fr

5 CHU Clermont-Ferrand, Service d'Immunologie, CHU Gabriel-Montpied, 58 Rue Montalembert, F63003 Clermont-Ferrand, France; bevrard@chu-clermontferrand.fr

6 UFR Médecine, Unité ECREIN, Clermont Université, Université d'Auvergne, UMR 1019, UNH, F-63003 Clermont-Ferrand, France

7 Unité Fonctionnelle de Pneumologie et Allergologie Pédiatrique, Hôpital Robert Debré, 48 Boulevard Sérurier, F-75019 Paris, France; flore.amat@aphp.fr

* Correspondence: e_rochette@chu-clermontferrand.fr; Tel.: +33-(0)4-73-75-22-97

\begin{abstract}
Background: We set out to assess the risk factors for asthma outcome in a cohort of infants who experienced their first episode of acute bronchiolitis. Methods: A cohort of 222 infants who were included during a first episode of acute bronchiolitis was prospectively followed. Herein, we present the results of their assessments (symptom history, skin prick tests, specific IgE assay, respiratory function tests) at age seven. Results: Of the 68/222 (30.6\%) children assessed at age seven, $15(22.05 \%)$ presented with asthma and were mainly males $(p=0.033), 14(20 \%)$ had respiratory allergies, $17(25 \%)$ presented atopic dermatitis and none had a food allergy. Family history of atopy was associated with asthma and sensitisation to aeroallergens at age seven ( $p=0.003, p=0.007)$. Rhinovirus (hRV) infection and rhinovirus/respiratory syncytial virus (RSV) co-infection were significantly associated with asthma at age seven $(p=0.035, p=0.04)$, but not with the initial severity of bronchiolitis. Eosinophil counts at ages three and seven were significantly higher in the asthmatics ( $p=0.01$, $p=0.046)$. Conclusion: Any infant, especially male, presenting a first episode of acute bronchiolitis due to hRV with a family history of atopy should be closely monitored via follow-up due to a higher risk for asthma at school age.
\end{abstract}

Keywords: acute bronchiolitis; rhinovirus; respiratory syncytial virus; atopy; asthma

\section{Introduction}

Acute bronchiolitis is the most common cause of lower respiratory tract infections in the first year of life. The viruses that are mainly responsible are the respiratory syncytial virus (RSV), which is associated with a more severe disease, and the rhinovirus (hRV), which is associated with more moderate forms of disease but a higher risk of asthma during childhood [1,2]. Most children have a moderate form of the disease, which is usually managed on an outpatient basis. Meanwhile, hospitalisation is required for severe forms of the disease $[3,4]$. 
Asthma is a common disease in the paediatric population, with a prevalence of approximately $8.3 \%$ among children aged $0-17$ years in the USA [5], and $11 \%$ in France [6]. The prevalence decreases with age, with a higher rate of recurrent wheezing in the younger age groups [7].

A few prospective studies have been conducted on asthma after acute bronchiolitis, with the type of virus involved and familial atopic status appearing as determinant factors. In the available cohorts, RSV is associated with severe initial infection and viral recurrent wheezing in the first years of life, whereas $\mathrm{hRV}$ is associated with long term asthma genesis in an atopic context. However, the available cohorts were conducted specifically in severe cases, notably in hospitalized cases $[7,8]$. To our knowledge, no prospective study has been conducted to date focusing on an acute bronchiolitis population, regardless of its severity, including mild forms managed at home [7]. Predicting the risk of asthma later in life in infants is difficult [9]. Thus, using a phenotype approach for the early identification of children at risk for asthma in the long-term is crucial.

We prospectively followed a cohort of infants aged under one year with a first episode of acute bronchiolitis, either hospitalised or cared for at home [10]. Herein, we present the results of their assessments at age seven. The aim of our prospective cohort study of infants with acute bronchiolitis was to evaluate the roles of early viral infections (particularly the types of viruses involved and the severity of the infection), as well as the overall aeroallergen sensitisations and their associations with asthma at age seven.

\section{Materials and Methods}

\subsection{Study Design}

A cohort of infants aged under one year consulting for their first episode of acute bronchiolitis during the 2011-2012 winter epidemic season at the University Hospital of Clermont-Ferrand (Clermont-Ferrand, Rhône-Alpes Auvergne, France) was prospectively re-assessed at age seven in 2019.

\subsection{Ethics}

All the children and their parents gave written informed consent for their participation and follow-up at three and seven years old. The research protocol for this study was previously approved by our institutional review board (Comité de Protection des Personnes Nord Ouest IV, France, Approval No. 2018-A02659-46).

\subsection{Study Population}

All children aged under one year presenting at the Paediatric Emergency Department for a first episode of acute bronchiolitis were considered for inclusion, from the mild forms managed in primary care to the most severe forms admitted to an intensive care unit. Infants with bronchopulmonary dysplasia, history of prematurity under 34 weeks, cystic fibrosis, known immune deficiencies, suspected primary ciliary dyskinesia, congenital heart disease or acute renal failure were excluded from the study. At the inclusion, the most common pathogen was RSV, which was found in 166 samples (76\%). Meanwhile, HRVs were found in 72 of the samples (33\%). Co-infection with RSV and HRV was detected in 41 patients (19\%) [10]. We first re-evaluated the children three years after inclusion. At this point in the follow-up, $46.8 \%$ presented with recurrent bronchial obstruction [11]. Only a family history of atopy was associated with asthma, and not the type of virus involved or the severity of acute bronchiolitis episode. RSV-hRV co-infection was associated with aeroallergen sensitisation.

The variables recorded at inclusion have been described elsewhere [10]. Briefly, demographic data were first obtained from the parents using a structured questionnaire. Acute bronchiolitis was defined as mild, moderate or severe according to a severity score calculated from $\mathrm{SpO}_{2}$, respiratory rate and respiratory effort on admission (Wainwright score [12]). The infants were hospitalised according to the French Guidelines (HAS 2019 [13]). Hospitalisation was required for young infants aged under six weeks and/or 
experiencing respiratory distress, major deterioration in general condition, risk of clinical dehydration or compromised home care (familial socio-economic context or limited use of care due to geographic location of the domicile). A nasopharyngeal aspirate was collected either in the emergency room or within the first $24 \mathrm{~h}$ following admission to detect respiratory viruses [10]. A telephone survey was also conducted. The parents of each child were contacted every three months until age three. A standardised questionnaire designed to elicit information on respiratory symptoms was used at every interview.

At age three, a complete medical check-up with an immunological profile was performed at the Outpatients Department of CHU-Estaing Hospital [11]. Familial atopy history was considered in cases of personal atopy history (eczema, rhinoconjunctivitis, food anaphylaxis or asthma) in one parent, sister or brother. At age seven, the parents of each child assessed at age three were contacted for a new assessment. The patient was declared lost to follow-up after three fruitless phone calls.

\subsection{Clinical Data}

At age seven, a clinical questionnaire was administered to assess data on respiratory symptoms (day or night cough, discomfort during exercise, use of salbutamol), respiratory treatments (corticosteroid p.o. or inhaled, long-acting bronchodilator), hospitalisation for asthma, wheezing outside viral episodes, personal atopy (presence of atopic dermatitis, eczema, rhinoconjunctivitis, food anaphylaxis from birth), environmental exposure to tobacco smoke (currently or during pregnancy), pets, type of housing, day-care attendance and number of siblings. Sociodemographic data were also collected, including sex, weight, height, and assessment of precariousness using the EPICES (Assessment of Precariousness and Health Inequalities in Health Examination Centers) questionnaire [14]. According to the French Health Authority, 'precariousness' is defined as a state of social instability characterised by the loss of one or more of those securities, particularly employment, that enable individuals and families to assume their professional, family and social responsibilities and enjoy their fundamental rights. Precariousness can thus manifest itself in several areas, such as income, housing, employment, educational qualifications, social protection, leisure, culture and health. A score of over 30 was taken as indicative of precariousness. Physical examination data, including symptoms of asthma, existence of eczema or signs of rhinoconjunctivitis and chest deformity were also collected.

\subsection{Pulmonary Function Testing}

Spirometry was performed using the Jaeger MasterScreeen. The spirometer was calibrated each morning using a 3-litre syringe. A nose clip was applied, and the children underwent a forced vital capacity (FVC) test in accordance with the American Thoracic Society/European Thoracic Society 2005 spirometry standards [15]. For each child, we set out to obtain three FVC manoeuvres that meet the ATS/ERS acceptability criteria. The forced expiratory volume in $1 \mathrm{~s}$ (FEV1), forced vital capacity (FVC), peak expiratory flow (PEF), maximum mid-expiratory flow (MMEF), forced expiratory flow (FEF), maximum expiratory flow (MEF) and maximum expiratory flow at 25\%,50\% and 75\% expiratory volumes (MEF 25, MEF 50, MEF 75) were measured.

Interrupter resistance (Rint) was measured using a Spiro Dyn apparatus (Spiro Dyn'R, Toulouse) calibrated daily for flow. Rint was measured during a 100-ms occlusion during expiration. While the measurements were carried out, each child was seated and asked to breathe quietly, connected to the flowmeter by a mouthpiece. Measurements were made with the child's head held in the neutral position, with the cheeks and chin held by the physician. The examinations were performed with and without a bronchodilator. For bronchodilator response, $400 \mu \mathrm{g}$ of salbutamol was inhaled through the spacer device. Fifteen minutes after the administration of the drug, each child underwent further spirometry to evaluate the bronchodilator response. 
Normal pattern was defined by normal FVC and normal $\mathrm{FEV}_{1} / \mathrm{FVC}$ ratios. Significant obstructive airflow disorder was defined by $\mathrm{FEV}_{1} / \mathrm{FVC}<0.8$. We considered significant reversibility for an increase of $12 \%$ in $\mathrm{FEV}_{1}$ or a decrease of $35 \%$ in Rint [16].

\subsection{Biological Assessment}

Prick tests were carried out by the same trained clinical research nurse to optimise reproducibility. Skin prick tests included histamine and isotonic saline as controls, main aeroallergens (Dermatophagoides pteronyssinus, Dermatophagoides farinae, Alternaria, timothy grass, birch, cats, dogs) and main trophallergens (egg, peanut, walnut, almond, hazelnut, soy). Papule diameter was measured at $20 \mathrm{~min}$. The prick test was considered positive with a diameter equal to or larger than $3 \mathrm{~mm}$ compared with the control. Sensitisations to aeroallergens and trophallergens were confirmed by a unitary assay of specific serum IgE by ImmunoCAP (Phadia $250^{\circledR}$, Phadia AB, Uppsala, Sweden). ImmunoCap Phadia $250^{\circledR}$ provides a quantitative result ranging from 0.1 to $100 \mathrm{kUA} / \mathrm{L}$. We took $0.35 \mathrm{kUA} / \mathrm{L}$ as the positive threshold. Multi-sensitisation was defined if the tests (SPT or IgE assay) were positive for at least two allergens, except for co-sensitisation to Dermatophagoides pteronyssinus and Dermatophagoides farinae, which was considered as monosensitisation. A blood test was performed to assess eosinophilia, defined for levels up to $0.300 \mathrm{G} / \mathrm{L}$ [17].

\subsection{Asthma Outcome}

Asthma was defined according to the frequency of the following symptoms: asthma symptoms (tachypnea, wheezing, expiratory stridor, respiratory chest retraction), and doctor-diagnosed wheezes or use of anti-asthmatic medication with a medical prescription. If $\geq 3$ respiratory symptoms were documented $\geq 2$ times or if any such episode lasted $\geq 4$ weeks, then the subject was classified as having asthma [18,19].

\subsection{Statistical Analysis}

Statistics were computed using Stata v15 (StataCorp, College Station, TX, USA). The study sample was described by frequency and associated percentage for categorical data and by mean \pm standard deviation, by deviation when the data were normally distributed or by median and interquartile range (IQR) for continuous data. Univariate analysis of asthma was conducted using the chi-squared test (or Fisher's exact test when appropriate) for categorical data and using Student's $t$-test (or the Mann-Whitney test when data were non-normal) for continuous data. Results are shown as odds ratio with $95 \%$ confidence interval. The same methods were used to analyse associations between the development of allergic sensitisation and the patient's characteristics, as well as for asthma analysis in the subgroup of patients with aeroallergen sensitisation. All the tests were two-sided, and a $p$-value $<0.05$ was considered significant.

\section{Results}

Overall, 222 children were initially recruited (2011-2012). Of this number, 154/222 $(69.4 \%)$ were assessed at age three in 2014-2015. Finally, 68/222 (30.6\%) completed the entire follow-up period at age seven in 2019.

The children who were lost to follow-up (Table 1) did not differ significantly from those assessed at age seven in terms of sex, gestational age at birth, family history of asthma, passive tobacco smoking, initial severity of bronchiolitis and initial care for acute bronchiolitis (hospitalisation or ambulatory care). 
Table 1. Characteristics of the population: children lost to follow-up/children assessed at age 7.

\begin{tabular}{|c|c|c|c|}
\hline$n(\%)$ & $\begin{array}{l}\text { Lost to Follow-Up } \\
\quad N=154(69)\end{array}$ & $\begin{array}{c}\text { Children Assessed at Age } 7 \\
\quad N=68 \text { (31) }\end{array}$ & $p$-Value \\
\hline Male, $n(\%)$ & $88(57.14)$ & $43(63.24)$ & 0.395 \\
\hline Prematurity & $18(11.69)$ & $10(14.71)$ & 0.532 \\
\hline Caesarean & $14(20.9)$ & $8(14.04)$ & 0.319 \\
\hline Hospitalisation & $119(77.27)$ & $53(77.94)$ & 0.912 \\
\hline Reanimation & $7(4.55)$ & $4(5.88)$ & 0.740 \\
\hline Ventilator assistance & $58(37.66)$ & $28(41.18)$ & 0.620 \\
\hline Familial asthma & $40(32.79)$ & $25(37.31)$ & 0.531 \\
\hline Tobacco smoking in pregnancy $n(\%)$ & $18(26.87)$ & $8(13.11)$ & 0.053 \\
\hline
\end{tabular}

\subsection{Description of the Population}

The population of children assessed at age seven comprised mainly males (43/68; $63.2 \%)$ aged $7.68 \pm 0.3$ years. Median body mass index was $15.6 \mathrm{~kg} / \mathrm{m}^{2}( \pm 2.8 \mathrm{SD})$. With regards to acute bronchiolitis history at inclusion, four patients $(4 / 68 ; 5.8 \%)$ presented with severe acute bronchiolitis and were hospitalised at an intensive care unit. The others were mainly cared for in the hospital (53 children/68, 77.9\%). The viruses involved were RSV in $76.4 \%$, hRV in $23.5 \%$ and RSV-hRV co-infection in $10.3 \%$ of the cases. Twenty-six children $(26 / 68 ; 38.2 \%)$ were currently exposed to tobacco smoking and 10/68 $(14.7 \%)$ during pregnancy. Fifty-six children (56/68; 82.3\%) lived in houses and 12/68 (17.7\%) in apartments. Animals were present at home for $48 / 68$ (70.6\%) of the subjects and cats for $25 / 68$ of them $(36.8 \%)$. Precariousness was suspected based on the EPICES score of seven patients $(7 / 68 ; 10.3 \%)$.

\subsection{Asthma}

We found an asthma rate of $22.05 \%$ in our population ( $n=15 / 68$ children). Twelve $(12 / 15 ; 80 \%)$ have presented asthma since age three. Three $(3 / 15 ; 20 \%)$ developed asthma at school age. Four children $(4 / 68 ; 5.9 \%)$ had already been hospitalised for an asthma attack, $10(10 / 68 ; 14.7 \%)$ had wheezing episodes outside of a viral episode, $32(32 / 68$; $47 \%)$ received occasional treatments with salbutamol and $16(16 / 68 ; 23.5 \%)$ took daily background therapy. Independent of the validated asthma diagnosis, several children had already received anti-asthmatic treatment; one of them was not asthmatic at age seven. Regarding respiratory functional exploration, none of the children had any obstructive ventilation disorder $\left(\mathrm{FEV}_{1} 104 \% \pm 9 \%, \mathrm{FEV}_{1} / \mathrm{FVC} 107 \% \pm 6\right.$ (mean $\left.\pm \mathrm{SD}\right)$ ). We noted significant reversibility in 16 children $(16 / 68 ; 23.5 \%$ of our population), having observed it in five asthmatic patients $(5 / 15 ; 33 \%)$ and in 11 non-asthmatics $(11 / 53 ; 21 \%)$.

\subsection{Allergy and Sensitisation}

We noted an atopic family history for 47 patients $(47 / 68 ; 69.1 \%)$. Seventeen patients $(17 / 68 ; 25 \%)$ presented atopic dermatitis history, $14(14 / 68 ; 20.1 \%)$ allergic respiratory symptoms and none had a food allergy.

Seven of the asthmatic patients were sensitised to an aeroallergen $(p=0.009)$ and none to a trophallergen. With regards to aeroallergens, we highlighted a sensitisation to mites in 10 children $(10 / 68 ; 14.7 \%)$, to Alternaria alternata in two $(2 / 68 ; 2.9 \%)$, to grasses in seven $(7 / 68 ; 10.3 \%)$, to timothy grasses in five $(5 / 68 ; 7.3 \%)$ and to cats in five $(5 / 68 ; 7.3 \%)$ (Table 2). 
Table 2. Aeroallergen sensitisation profiles.

\begin{tabular}{lccc}
\hline & $\begin{array}{c}\text { Asthma } \\
\mathbf{N = \mathbf { 1 5 }}\end{array}$ & $\begin{array}{c}\text { No Asthma } \\
\boldsymbol{N}=\mathbf{5 3}\end{array}$ & $p$-Value \\
\hline Aeroallergen sensitisation $n(\%)$ & $8 / 15(53)$ & $8 / 53(15)$ & 0.009 \\
Mites $n(\%)$ & $4(27)$ & $6(11)$ & 0.21 \\
Alternaria alternata $n(\%)$ & $1(7)$ & $1(2)$ & 0.395 \\
Grasses $n(\%)$ & $3(20)$ & $4(8)$ & 0.18 \\
Timothy $n(\%)$ & $2(13)$ & $3(6)$ & 0.303 \\
Cats $n(\%)$ & $2(13)$ & $3(6)$ & 0.303 \\
\hline
\end{tabular}

A higher eosinophil count was observed in active asthmatics aged seven, evaluated at ages three and seven (Table 3). Eosinophilia considered as an eosinophil count with $\geq 300$ cells $\mu \mathrm{L}^{-1}$ did not differ, evaluated at ages three $(p=0.361)$ and seven $(p=0.178)$.

Table 3. Factors associated with asthma at age 7.

\begin{tabular}{|c|c|c|c|}
\hline & $\begin{array}{l}\text { Asthma } \\
N=15\end{array}$ & $\begin{array}{c}\text { No Asthma } \\
\qquad N=53\end{array}$ & $p$-Value \\
\hline \multicolumn{4}{|l|}{ Sex } \\
\hline Male, $n(\%)$ & $13(86.67)$ & $30(56.6)$ & 0.033 \\
\hline \multicolumn{4}{|l|}{ Causal virus at inclusion } \\
\hline$h R S V n(\%)$ & 11(73) & $41(79)$ & 0.73 \\
\hline$h R V n(\%)$ & $7(47)$ & $9(17)$ & 0.035 \\
\hline$h R S V-h R V n(\%)$ & $4(27)$ & $3(6)$ & 0.04 \\
\hline Family allergy history $n(\%)$ & $15(100)$ & $32(61)$ & 0.003 \\
\hline \multicolumn{4}{|l|}{ Personal atopic history } \\
\hline Rhinitis $n(\%)$ & $7(47)$ & $4(8)$ & 0.001 \\
\hline Respiratory allergy $n(\%)$ & $7(47)$ & $13(24)$ & 0.009 \\
\hline Eosinophils at 3 years (G/L mean $[95 \%$ CI]) & $0.239[0.178 ; 0.350]$ & $0.163[0.091 ; 0.212]$ & 0.01 \\
\hline Eosinophils at 7 years ( $\mathrm{G} / \mathrm{L}$ mean $[95 \% \mathrm{CI}])$ & $0.490[0.180 ; 0.800]$ & $0.255[0.130 ; 0.515]$ & 0.046 \\
\hline \multicolumn{4}{|l|}{ Environmental exposures } \\
\hline Tobacco smoking during pregnancy $n(\%)$ & $4(27)$ & $6(11)$ & 0.21 \\
\hline Passive tobacco smoking $n(\%)$ & $5(33)$ & $30(56.6)$ & 0.658 \\
\hline Cat $n(\%)$ & $5(33)$ & $20(38)$ & 0.755 \\
\hline
\end{tabular}

\subsection{Risk Factors for Asthma and Sensitisation in the Long Term}

In the univariate analysis, being male, having a family history of allergy, rhinovirus infection or rhinovirus-RSV acute bronchiolitis and greater blood eosinophilia assessed at ages three and seven were associated with asthma at age seven (Table 3). The initial severity of acute bronchiolitis was not associated with asthma at age seven using the Wainwright score $(p=0.457)$, the hospitalisation variable $(p=0.73)$ or the intensive care requirement $(p=0.57)$. Exposure to tobacco smoke (currently or during pregnancy), precariousness or the presence of a cat at home during infancy was not associated with asthma at age seven.

Only family history of atopy seemed to be associated with the development of allergic sensitisation $(p=0.017)$. Initial infections with hRV or RSV-hRV were not significantly associated with sensitisation at age seven ( $p=0.506$ and $p=0.345$, respectively). Notably, exposure to tobacco smoke (currently or during pregnancy) was not linked with the development of sensitisation at age seven $(p=0.604$ and $p=0.047)$.

\section{Discussion}

In this prospective cohort study of infants presenting a first episode of acute bronchiolitis before one year old, we sought to extend our previous findings on the roles of early viral infections, as well as overall aeroallergen sensitisations and their associations with asthma at age seven. This is the first prospective study that included mild to severe cases, care at home or hospitalised, and with a long-term follow up. 


\subsection{Asthma Development}

We found a asthma development rate of $22 \%$, which is comparable to the few other cohorts available of infants hospitalised for acute bronchiolitis (15-34\%) $[8,19,20]$. Most of the patients presented normal respiratory function, but with airway hyperresponsiveness (AHR) without active symptomatic asthma. This could be the consequence of remodelling and structural changes in connection with their previous symptomatic asthma [21]. These patients were not considered asthmatic in the absence of symptoms.

\subsection{Asthma and Risk Factors}

The main factors predicting asthma development for these children seemed to be male sex, family history of allergy and rhinovirus infection, isolated or in association with RSV. Moreover, the risk of sensitisation to aeroallergen at age seven seemed to be correlated only with family history of atopy.

Notably, the male sex had already been reported as a risk factor for wheezing [22].

Rather than acute bronchiolitis severity, the causal virus involved seems to play a main role in asthma genesis and its phenotype in the long term with two distinct trajectories. At preschool age, the predominant asthma phenotype is the viral recurrent wheezer, with a significant decrease in prevalence at school age and a low risk of chronic obstructive pulmonary disease (COPD) in adulthood $[23,24]$. As several studies have already shown [21,23-26], RSV induces more severe initial infections and is involved in the genesis of viral recurrent wheezers, which become minority phenotypes beyond five years old. In our study which evaluated children at school age, acute bronchiolitis due to rhinovirus infection (associated or not with RSV) was associated with active asthma at age seven. Although the precise mechanism is still unclear, the impact of hRV seems to be linked to family atopy status. Both allergic sensitisation and rhinovirus-induced wheezing illnesses in early life increase asthma risk in the long term. Allergic sensitisation could result in a decreased innate immune response to hRV that could generate greater degrees of airway inflammation and the potential for airway remodelling and loss of lung function over time $[27,28]$. Our results are consistent with atopic status (represented by familial atopic history) and $\mathrm{hRV}$ infection having major roles in long-term asthma genesis. In addition, the first $h R V$ acute bronchiolitis in an atopic infant should be considered as a predictive factor of persistent atopic asthma at school age, as represented by mild allergic asthma and severe asthma with multiple allergic comorbidities $[29,30]$. These infants require the specific attention of paediatricians in the long term due to the risk of COPD development for those phenotypes.

\subsection{Allergy and Sensitisation}

The importance of parental atopy has been shown previously [31]. Having one atopic parent leads to atopic disease development in $20-40 \%$ of children, which rises to $40-60 \%$ if both parents are atopic. Independent of the virus involved, family history of atopy appears to be the main risk factor for the development of asthma or personal atopy [32]. This is one of the main criteria in many risk algorithms for asthma development $[33,34]$. In our subjects, all of the sensitised children had a family history of atopy.

\subsection{Type 2 Inflammation Marker}

Early eosinophilia stands out as a potential risk factor for persistent asthma. T2 eosinophilic inflammation is most commonly associated with atopy and allergic asthma [35,36]. Eosinophils release proinflammatory cytokines, leukotrienes [30] and specific basic proteins that are responsible for the damage inflicted on the bronchial epithelium. Several studies suggest that an eosinophil count $\geq 300$ cells $\mu \mathrm{L}^{-1}$ in young children could be considered a risk factor $[37,38]$. Eosinophilia seems to predict wheezing at school age and is correlated with asthma severity, including exacerbation severity and corticosteroid response $[32,36,39,40]$. In our study, eosinophils were significantly higher in the asthmatic population at each evaluation (age three, age seven). The cut-off of the count 
$\geq 300$ cells $\mu \mathrm{L}^{-1}$ was not significant, possibly owing to our restricted asthmatic population. However, all of these observations argue for an early eosinophil assay to identify infants at risk of persistent and severe asthma. The environment plays a primordial role in asthma genesis, particularly tobacco smoking $[25,28]$. Contrary to literature data, environmental exposure represented by post-natal passive tobacco smoking, in utero passive tobacco smoking, cat exposure and precariousness were not associated with asthma at age seven in our study. The sample size of our cohort that completed the follow-up is too limited to evaluate their impacts on asthma genesis [23,26,29].

\subsection{Study Limitations}

Finally, the size of our population is clearly the main limitation of our study. Many infants were lost to follow-up during the study. The consequences are not negligible for our results, with a lack of power and a possible selection bias to clearly identify the risk factors for asthma development in the long term (especially eosinophilia or tobacco smoking exposure, as specified previously). Likewise, multivariate analysis could not be performed to confirm univariate results and could be a source of confounding bias. Nevertheless, our results are in line with previous cohort studies and provide additional long-term data pertaining to children with acute bronchiolitis during infancy, including those without atopic familial history and with mild to moderate forms of disease. A case control study with children who did not have acute bronchiolitis during infancy could precisely determine the risk factors for asthma development in the long term after an episode of acute bronchiolitis.

\section{Conclusions}

Precise pneumological assessments should be conducted to identify infants who are at higher risk of asthma in the long term during a first episode of acute bronchiolitis, regardless of its severity. The aim of early phenotyping with virology and atopic status assessment is to identify at an early stage infants who are at risk for asthma development in the long term, because of the COPD risk present in asthma phenotypes active after school age. Thus, paediatricians should offer to those patients personalised prevention, follow-up and treatment.

Any infant, especially male, presenting a first episode of acute bronchiolitis due to hRV with a family history of atopy should be closely monitored via follow-up because of a higher risk for asthma at school age and the potential sequelae in adulthood with COPD development.

Author Contributions: Conceptualization, C.E. and E.R.; methodology, C.E. and E.R.; validation, C.E.; formal analysis, A.M.; investigation, J.M., V.J., F.A., B.E. and C.E.; resources, A.U.; data curation, J.M. and C.E.; writing-original draft preparation, J.M.; writing-review and editing, J.M. and C.E.; supervision, C.E. All authors have read and agreed to the published version of the manuscript.

Funding: This research received no external funding.

Institutional Review Board Statement: The study was conducted according to the guidelines of the Declaration of Helsinki and approved by the Ethics Committee Nord Ouest IV in France (Approval No. 2018-A02659-46, 16 March 2019).

Informed Consent Statement: Informed consent was obtained from all subjects involved in the study.

Data Availability Statement: The datasets used and/or analysed during the current study are available from the corresponding author upon reasonable request.

Conflicts of Interest: The authors declare no conflict of interest. 


\section{References}

1. Marguet, C.; Lubrano, M.; Gueudin, M.; Le Roux, P.; Deschildre, A.; Forget, C.; Couderc, L.; Siret, D.; Donnou, M.-D.; Bubenheim, M.; et al. In Very Young Infants Severity of Acute Bronchiolitis Depends on Carried Viruses. PLoS ONE 2009, 4, e4596. [CrossRef] [PubMed]

2. Freymuth, F.; Vabret, A.; Dina, J.; Cuvillon-Nimal, D.; Lubin, C.; Vaudecrane, A.; Guillois, B.; Gouarin, S.; Petitjean, J.; LafaixDelaire, F.; et al. Bronchiolitis viruses. Arch. Pediatr. Organe Off. Soc. Fr. Pediatr. 2010, 17, 1192-1201. [CrossRef] [PubMed]

3. Meissner, H.C. Viral Bronchiolitis in Children. N. Engl. J. Med. 2016, 374, 62-72. [CrossRef] [PubMed]

4. Green, C.A.; Yeates, D.; Goldacre, A.; Sande, C.; Parslow, R.C.; McShane, P.; Pollard, A.J.; Goldacre, M.J. Admission to Hospital for Bronchiolitis in England: Trends over Five Decades, Geographical Variation and Association with Perinatal Characteristics and Subsequent Asthma. Arch. Dis. Child. 2016, 101, 140-146. [CrossRef] [PubMed]

5. Zahran, H.S.; Bailey, C.M.; Damon, S.A.; Garbe, P.L.; Breysse, P.N. Vital Signs: Asthma in Children-United States, $2001-2016$. MMWR Morb. Mortal. Wkly. Rep. 2018, 67, 149-155. [CrossRef] [PubMed]

6. Delmas, M.-C.; Guignon, N.; Leynaert, B.; Moisy, M.; Marguet, C.; Fuhrman, C. Increase in asthma prevalence among young children in France. Rev. Mal. Respir. 2017, 34, 525-534. [CrossRef]

7. Garcia-Garcia, M.L.; Calvo Rey, C.; Del Rosal Rabes, T. Pediatric Asthma and Viral Infection. Arch. Bronconeumol. 2016, 52, 269-273. [CrossRef]

8. Wang, G.; Han, D.; Jiang, Z.; Li, M.; Yang, S.; Liu, L. Association between Early Bronchiolitis and the Development of Childhood Asthma: A Meta-Analysis. BMJ Open 2021, 11, e043956. [CrossRef]

9. Clough, J.B.; Keeping, K.A.; Edwards, L.C.; Freeman, W.M.; Warner, J.A.; Warner, J.O. Can We Predict Which Wheezy Infants Will Continue to Wheeze? Am. J. Respir. Crit. Care Med. 1999, 160, 1473-1480. [CrossRef]

10. Amat, F.; Henquell, C.; Verdan, M.; Roszyk, L.; Mulliez, A.; Labbé, A. Predicting the Severity of Acute Bronchiolitis in Infants: Should We Use a Clinical Score or a Biomarker? J. Med. Virol. 2014, 86, 1944-1952. [CrossRef]

11. Amat, F.; Plantard, C.; Mulliez, A.; Petit, I.; Rochette, E.; Verdan, M.; Henquell, C.; Labbé, G.; Heraud, M.C.; Evrard, B.; et al. RSV-HRV Co-Infection Is a Risk Factor for Recurrent Bronchial Obstruction and Early Sensitization 3 Years after Bronchiolitis. J. Med. Virol. 2018, 90, 867-872. [CrossRef]

12. Wainwright, C.; Altamirano, L.; Cheney, M.; Cheney, J.; Barber, S.; Price, D.; Moloney, S.; Kimberley, A.; Woolfield, N.; Cadzow, S.; et al. A Multicenter, Randomized, Double-Blind, Controlled Trial of Nebulized Epinephrine in Infants with Acute Bronchiolitis. N. Engl. J. Med. 2003, 349, 27-35. [CrossRef]

13. HAS. Prise En Charge Du Premier Épisode de Bronchiolite Aiguë Chez Le Nourrisson de Moins de 12 Mois Méthode Recommandations Pour La Pratique Clinique; HAS: Saint-Denis, France, 2019.

14. Sass, C.; Guéguen, R.; Moulin, J.-J.; Abric, L.; Dauphinot, V.; Dupré, C.; Giordanella, J.-P.; Girard, F.; Guenot, C.; Labbé, É.; et al. Comparaison du score individuel de précarité des Centres d'examens de santé, EPICES, à la définition socio-administrative de la précarité. Sante Publique 2006, 18, 513-522. [CrossRef]

15. Standardisation of Spirometry I European Respiratory Society. Available online: https://erj.ersjournals.com/content/26/2/319 .long (accessed on 6 July 2020).

16. Beydon, N.; Matecki, S. L'exploration Fonctionnelle Respiratoire du Jeune Enfant; La Lettre du Pneumologue-Vol. XVIII- ${ }^{\circ}$ 3-mai-juin 2015. Available online: https:/ / www.edimark.fr/Front/frontpost/getfiles/23025.pdf (accessed on 26 September 2021).

17. Ortega, H.G.; Liu, M.C.; Pavord, I.D.; Brusselle, G.G.; FitzGerald, J.M.; Chetta, A.; Humbert, M.; Katz, L.E.; Keene, O.N.; Yancey, S.W.; et al. Mepolizumab Treatment in Patients with Severe Eosinophilic Asthma. N. Engl. J. Med. 2014, 371, 1198-1207. [CrossRef]

18. Hovland, V.; Riiser, A.; Mowinckel, P.; Carlsen, K.-H.; Carlsen, K.C.L. The Significance of Early Recurrent Wheeze for Asthma Outcomes in Late Childhood. Eur. Respir. J. 2013, 41, 838-845. [CrossRef]

19. Jackson, D.J.; Gangnon, R.E.; Evans, M.D.; Roberg, K.A.; Anderson, E.L.; Pappas, T.E.; Printz, M.C.; Lee, W.-M.; Shult, P.A.; Reisdorf, E.; et al. Wheezing Rhinovirus Illnesses in Early Life Predict Asthma Development in High-Risk Children. Am. J. Respir. Crit. Care Med. 2008, 178, 667-672. [CrossRef] [PubMed]

20. Korppi, M.; Kuikka, L.; Reijonen, T.; Remes, K.; Juntunen-Backman, K.; Launiala, K. Bronchial Asthma and Hyperreactivity After Early Childhood Bronchiolitis or Pneumonia: An 8-Year Follow-up Study. Arch. Pediatr. Adolesc. Med. 1994, 148, 1079-1084. [CrossRef]

21. Kariyawasam, H.H.; Aizen, M.; Barkans, J.; Robinson, D.S.; Kay, A.B. Remodeling and Airway Hyperresponsiveness but Not Cellular Inflammation Persist after Allergen Challenge in Asthma. Am. J. Respir. Crit. Care Med. 2007, 175, 896-904. [CrossRef] [PubMed]

22. Tse, S.M.; Coull, B.A.; Sordillo, J.E.; Datta, S.; Gold, D.R. Gender- and Age-Specific Risk Factors for Wheeze from Birth through Adolescence. Pediatr. Pulmonol. 2015, 50, 955-962. [CrossRef]

23. Csonka, P.; Kaila, M.; Laippala, P.; Kuusela, A.L.; Ashorn, P. Wheezing in Early Life and Asthma at School Age: Predictors of Symptom Persistence. Pediatr. Allergy Immunol. Off. Publ. Eur. Soc. Pediatr. Allergy Immunol. 2000, 11, 225-229. [CrossRef] [PubMed]

24. Just, J.; Bourgoin-Heck, M.; Amat, F. Clinical Phenotypes in Asthma during Childhood. Clin. Exp. Allergy 2017, 47, 848-855. [CrossRef]

25. Toskala, E.; Kennedy, D.W. Asthma Risk Factors. Int. Forum Allergy Rhinol. 2015, 5, S11-S16. [CrossRef] 
26. Schreier, H.M.C.; Chen, E. Socioeconomic Status and the Health of Youth: A Multi-Level, Multi-Domain Approach to Conceptualizing Pathways. Psychol. Bull. 2013, 139, 606-654. [CrossRef]

27. Chen, E.; Hanson, M.D.; Paterson, L.Q.; Griffin, M.J.; Walker, H.A.; Miller, G.E. Socioeconomic Status and Inflammatory Processes in Childhood Asthma: The Role of Psychological Stress. J. Allergy Clin. Immunol. 2006, 117, 1014-1020. [CrossRef]

28. Leynaert, B.; Le Moual, N.; Neukirch, C.; Siroux, V.; Varraso, R. Facteurs environnementaux favorisant le développement d'un asthme. Presse Méd. 2019, 48, 262-273. [CrossRef] [PubMed]

29. Ihuoma, H.; Belgrave, D.C.; Murray, C.S.; Foden, P.; Simpson, A.; Custovic, A. Cat Ownership, Cat Allergen Exposure, and Trajectories of Sensitization and Asthma throughout Childhood. J. Allergy Clin. Immunol. 2018, 141, 820-822.e7. [CrossRef]

30. Laidlaw, T.M.; Boyce, J.A. Cysteinyl Leukotriene Receptors, Old and New; Implications for Asthma. Clin. Exp. Allergy 2012, 42, 1313-1320. [CrossRef] [PubMed]

31. Polonovski, J.-M. Rhinite Allergique. Available online: https://www.stallergenesgreer.fr/les-facteurs-de-risque (accessed on 11 June 2020).

32. Rodríguez-Martínez, C.E.; Sossa-Briceño, M.P.; Castro-Rodriguez, J.A. Factors Predicting Persistence of Early Wheezing through Childhood and Adolescence: A Systematic Review of the Literature. J. Asthma Allergy 2017, 10, 83-98. [CrossRef] [PubMed]

33. Caudri, D.; Savenije, O.E.M.; Smit, H.A.; Postma, D.S.; Koppelman, G.H.; Wijga, A.H.; Kerkhof, M.; Gehring, U.; Hoekstra, M.O.; Brunekreef, B.; et al. Perinatal Risk Factors for Wheezing Phenotypes in the First 8 Years of Life. Clin. Exp. Allergy 2013, 43, 1395-1405. [CrossRef]

34. Henderson, J.; Granell, R.; Heron, J.; Sherriff, A.; Simpson, A.; Woodcock, A.; Strachan, D.P.; Shaheen, S.O.; Sterne, J.A. Associations of Wheezing Phenotypes in the First 6 Years of Life with Atopy, Lung Function and Airway Responsiveness in Mid-Childhood. Thorax 2008, 63, 974-980. [CrossRef] [PubMed]

35. Russell, R.J.; Brightling, C. Pathogenesis of Asthma: Implications for Precision Medicine. Clin. Sci. 2017, 131, 1723-1735. [CrossRef]

36. Papi, A.; Brightling, C.; Pedersen, S.E.; Reddel, H.K. Asthma. Lancet Lond. Engl. 2018, 391, 783-800. [CrossRef]

37. Anderson, H.M.; Lemanske, R.F.; Arron, J.R.; Holweg, C.T.J.; Rajamanickam, V.; Gangnon, R.E.; Gern, J.E.; Jackson, D.J. Relationships among Aeroallergen Sensitization, Peripheral Blood Eosinophils, and Periostin in Pediatric Asthma Development. J. Allergy Clin. Immunol. 2017, 139, 790-796. [CrossRef]

38. Castro-Rodríguez, J.A.; Holberg, C.J.; Wright, A.L.; Martinez, F.D. A Clinical Index to Define Risk of Asthma in Young Children with Recurrent Wheezing. Am. J. Respir. Crit. Care Med. 2000, 162, 1403-1406. [CrossRef]

39. Carr, T.F.; Berdnikovs, S.; Simon, H.-U.; Bochner, B.S.; Rosenwasser, L.J. Eosinophilic Bioactivities in Severe Asthma. World Allergy Organ. J. 2016, 9, 21. [CrossRef] [PubMed]

40. Sánchez-García, S.; Habernau Mena, A.; Quirce, S. Biomarkers in Inflammometry Pediatric Asthma: Utility in Daily Clinical Practice. Eur. Clin. Respir. J. 2017, 4, 1356160. [CrossRef] 